\title{
High-performance supercapacitors based on hierarchically porous carbons with a three- dimensional conductive network structure
}

\author{
Jizhao Zou, Wenxuan Tu, Shao-Zhong Zeng, Yuechao Yao, Qi Zhang, Hongliang \\ Wu, Tongbin Lan, Shiyu Liu and Xierong Zeng
}

\begin{abstract}
Clews of polymer nanobelts (CsPNBs) have the advantages of inexpensive raw materials, simple synthesis and large output. Novel clews of carbon nanobelts (CsCNBs) have been successfully prepared by carbonizing CsPNBs and by $\mathrm{KOH}$ activation subsequently. From the optimized process, CsCNBs*4, with a specific surface area of $2291 \mathrm{~m}^{2} \mathrm{~g}^{-1}$ and a pore volume of up to $1.29 \mathrm{~cm}^{3} \mathrm{~g}^{-1}$, has been obtained. Fundamentally, the CsCNBs possess a three-dimensional conductive network structure, a hierarchically porous framework, and excellent hydrophilicity, which enable fast ion diffusion through channels and a large enough ion adsorption/desorption surface to improve electrochemical performance of supercapacitors. The product exhibits a high specific capacitance of $327.5 \mathrm{~F} \mathrm{~g}^{-1}$ at a current density of $0.5 \mathrm{~A} \mathrm{~g}^{-1}$ in a three-electrode system. The results also reveal a high-rate capacitance $\left(72.2 \%\right.$ capacitance retention at $\left.500 \mathrm{mV} \mathrm{s}^{-1}\right)$ and stable cycling lifetime (95\% of initial capacitance after 15000 cycles). Moreover, $\mathrm{CsCNBs} * 4$ provides a high energy density of $29.8 \mathrm{~W} \mathrm{~h} \mathrm{~kg}$ at a power density of $345.4 \mathrm{~W} \mathrm{~kg}^{-1}$ in $1 \mathrm{M}$ tetraethylammonium tetrafluoroborate/acetonitrile $\left(\mathrm{TEABF}_{4} / \mathrm{AN}\right)$ electrolyte. These inspiring results imply that this carbon material with a three-dimensional conductive network structure possesses excellent potential for energy storage.
\end{abstract}




\section{Introduction}

As the market for electric vehicles and portable electronic devices grows rapidly, the storage of electrical energy is attracting increasing interest. During the past few decades, supercapacitors have been extensively studied because of their superior characteristics, such as their rapid chargedischarge rates, long cycle lives, wide operating temperature ranges, energy-saving potential and environmental friendliness. ${ }^{1-4}$ More importantly, due to the above characteristics, supercapacitors have been widely used in commercial and industrial equipment. $\frac{5.6}{6}$

However, compared to lithium-ion batteries, supercapacitors have low energy densities, which limit their future uses. Thus, the development of supercapacitors with high energy densities is urgently needed. Electrode materials play a very important role in the efficiency and practicality of supercapacitors. ${ }^{7}$ Therefore, the development of electrode materials with a high specific capacitance, good electrochemical stability and desirable cost benefit has attracted considerable interest. Carbon materials are more attractive than other materials due to their low cost, light weight, variety of

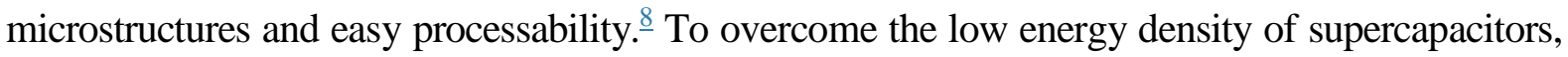
carbon materials need to have a porous structure with a high specific surface area and hierarchical pores. Therefore, activated carbon materials are a good choice because of their high porosity and specific surface area, excellent chemical stability, moderate cost, and high conductivity. ${ }^{9}$ With the growing social demand for efficient energy storage, the development of new activated carbon materials with high performance and novel structures is imperative..$^{10}$

Carbon nanotubes possess a typical one-dimensional nanostructure. Although their unique tubular structure facilitates ion transport, the high production cost and dispersion problems limit their widespread applications. ${ }^{11}$ Graphene materials, which are classic two-dimensional materials, exhibit high gravimetric performance because of their high surface areas and short ion diffusion paths. However, their poor volumetric performance and high synthesis costs can limit their further applications. ${ }^{12}$ In recent years, an increasing number of reports on the application of activated 
carbons with three-dimensional frameworks in supercapacitors have been published. ${ }^{13-18}$ These carbon materials with a three-dimensional framework, which integrate the advantages of a high specific surface area, hierarchical porous structure and good conductivity, can enhance the stability of the structure, shorten the ion transport path, and greatly reduce the charge transfer resistance. Therefore, it is possible to overcome the low-rate capability that results from kinetic ion transport issues and then obtain high energy density supercapacitors. ${ }^{19-21}$ Zeng et al. ${ }^{22,23}$ reported the synthesis of clews of polymer nanobelts (CsPNBs), which are a type of phenolic resin and have the advantages of inexpensive raw materials, simple synthesis and large output. Owing to the infusibility of the CsPNBs, their macroporous structure is maintained even after pyrolysis and extensive activation, leading to the formation of clews of carbon nanobelts (CsCNBs). Furthermore, CsCNBs with an ultrahigh specific surface area and porosity have excellent applications in high-rate lithium-sulfur batteries. However, such carbon materials have very poor hydrophilicity and exhibit a low capacity in aqueous electrolytes. $\mathrm{KOH}$ activation is an efficient and typical method for obtaining activated carbons with excellent hydrophilicity, high porosity and a large specific surface area. ${ }^{24}$

In this work, we demonstrate a facile and efficient two-step approach (carbonization and $\mathrm{KOH}$ activation) to the fabrication of hierarchically porous carbon materials for supercapacitors (Scheme 1). From the optimized process, CsCNBs $* 4$ with a specific surface area of $2291 \mathrm{~m}^{2} \mathrm{~g}^{-1}$ and a pore volume of up to $1.29 \mathrm{~cm}^{3} \mathrm{~g}^{-1}$ has been obtained. Fundamentally, the CsCNBs possess a threedimensional conductive network structure, a hierarchically porous framework, and excellent hydrophilicity, which provide fast ion diffusion through the channels and a large enough ion adsorption/desorption surface to improve electrochemical performance of supercapacitors. The product exhibits high specific capacitances of $327.5 \mathrm{~F} \mathrm{~g}^{-1}$ and $281.5 \mathrm{~F} \mathrm{~g}^{-1}$ at a current density of 0.5 $\mathrm{A} \mathrm{g}^{-1}$ in three- and two-electrode systems, respectively. Simultaneously, these results also reveal a high-rate capacitance $\left(72.2 \%\right.$ capacitance retention at $\left.500 \mathrm{mV} \mathrm{s}^{-1}\right)$ and stable cycling lifetime $(95 \%$ of the initial capacitance after 15000 cycles) in a three-electrode setup. Furthermore, sample 
CsCNBs*4 provides a high energy density of $29.8 \mathrm{~W} \mathrm{~h} \mathrm{~kg}^{-1}$ at a power density of $345.4 \mathrm{~W} \mathrm{~kg}^{-1}$ in a $1 \mathrm{M}$ tetraethylammonium tetrafluoroborate/acetonitrile $\left(\mathrm{TEABF}_{4} / \mathrm{AN}\right)$ electrolyte.

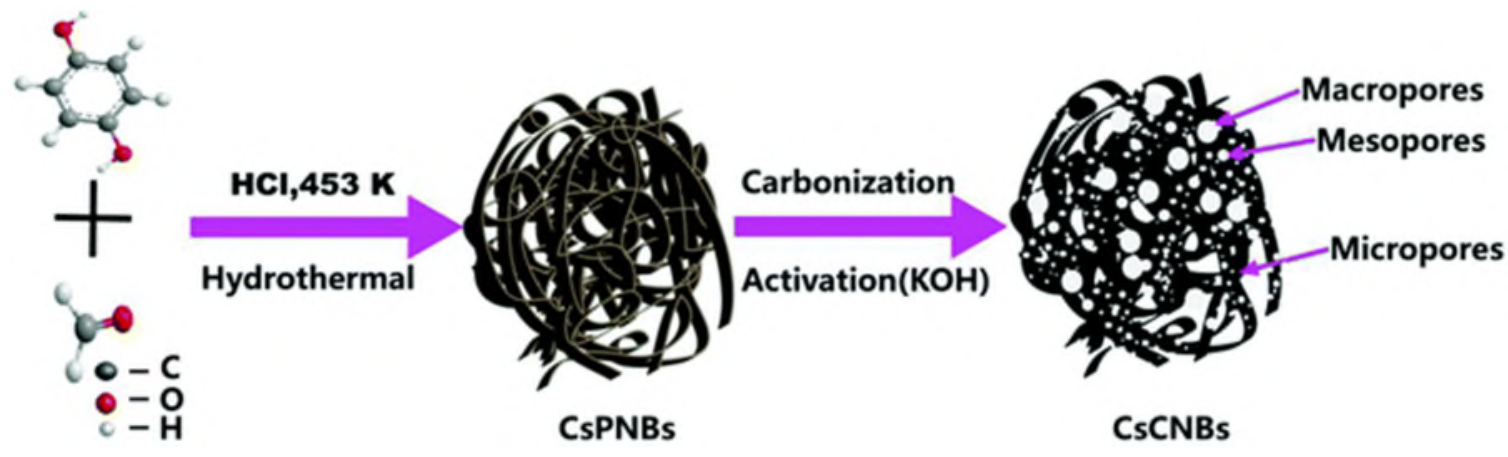

Scheme 1 Schematic illustration of the preparation of hierarchically porous CsCNBs.

\section{Materials and methods}

\subsection{Materials}

Hydroquinone (AR, 99\%), formaldehyde solution (AR, $37 \mathrm{wt} \%)$, concentrated hydrochloric acid solution (AR, $37 \mathrm{wt} \%)$ and $\mathrm{KOH}(\mathrm{GR}, 95 \%)$ were purchased from Shanghai Macklin Company (Shanghai, PR China) and used as received.

\subsection{Synthesis of CsPNBs}

Typically, $1.65 \mathrm{~g}$ of hydroquinone $(0.015 \mathrm{~mol}), 2.5 \mathrm{~mL}$ of a formaldehyde solution $(37 \mathrm{wt} \%)$ and $115 \mathrm{~mL}$ of a hydrochloric acid solution (10 wt $\%$ ) were mixed in a $200 \mathrm{~mL}$ autoclave lined with Teflon. The autoclave was then sealed and heated in an oven at $180{ }^{\circ} \mathrm{C}$ for $12 \mathrm{~h}$. The resulting black sponge-like products were filtered and washed with water. The filter cake was vacuum dried at $60{ }^{\circ} \mathrm{C}$ for $6 \mathrm{~h}$. Finally, $2.0 \mathrm{~g}$ of an airy, dark brown powder was collected. The yield was close to the quantitative value (based on hydroquinone).

\subsection{Preparation of CsCNBs}

First, $1.80 \mathrm{~g}$ of $\mathrm{CsPNBs}$ was heated to $800{ }^{\circ} \mathrm{C}$ under a flow of argon $(50 \mathrm{~mL}$ min -1$)$ with a heating rate of $5^{\circ} \mathrm{C} \mathrm{min}^{-1}$. When the temperature reached $800{ }^{\circ} \mathrm{C}$, the argon flow was continued, and the sample started to cool down. And the sample was named CsCNBs-800. After that, 0.40 $\mathrm{g}$ of the resultant material and a certain amount of $\mathrm{KOH}$ were mixed. The mixture was heated 
under a flow of $\operatorname{argon}\left(50 \mathrm{~mL} \mathrm{~min}{ }^{-1}\right)$ to $400{ }^{\circ} \mathrm{C}$ for $0.5 \mathrm{~h}$ and then at $800{ }^{\circ} \mathrm{C}$ for $1 \mathrm{~h}$ with a heating rate of $5{ }^{\circ} \mathrm{C} \mathrm{min}^{-1}$. The $\mathrm{KOH} / \mathrm{C}$ mass ratios were 3, 4 and 5 . And the samples were denoted according to the mass ratio as $\mathrm{CsCNBs}^{*} 3, \mathrm{CsCNBs} * 4$ and $\mathrm{CsCNB} * 5$, respectively. The clews of carbon nanobelts, named CsCNBs-950-40, were prepared by $\mathrm{CO}_{2}$ activation at $950{ }^{\circ} \mathrm{C}$ for 40 minutes according to ref. 23 .

\subsection{Characterization}

Field emission scanning electron microscopy (FESEM) images were obtained on a field emission SU-70 microscope. High-resolution transmission electron microscopy (HRTEM) images were obtained with a JEOL JEM2010 electron microscope. High-resolution X-ray diffraction (HR-XRD) patterns were recorded on a Bruker D8 Advance diffractometer using $\mathrm{Cu}-\mathrm{K} \alpha$ radiation $(40 \mathrm{kV}$ and $200 \mathrm{~mA}$ ). Confocal Raman spectra were recorded using a Renishaw InVia Raman microscope equipped with an argon-ion laser (514.5 $\mathrm{nm})$. Measurement of the Brunauer-Emmett-Teller (BET) specific surface areas was performed at $77 \mathrm{~K}$ using a low-temperature nitrogen adsorption surface area analyser (ASAP 2020, Micromeritics Ins, USA). The total pore volume and pore size distribution were calculated by a density functional theory (DFT) model. X-ray photoelectron spectroscopy (XPS) experiments were conducted on a Microlab 350 spectrometer employing a monochromatic Mg-Ka X-ray source. The electrochemical properties were tested on an electrochemical workstation (VMP300).

\subsection{Electrochemical measurements}

The electrochemical performance was characterized in a three-electrode system using $6 \mathrm{M}$ $\mathrm{KOH}$ as the electrolyte, a $\mathrm{Hg} / \mathrm{HgO}$ electrode as the reference electrode, and platinum foil as the counter electrode. The electrode materials were prepared by mixing the CsCNBs ( $85 \mathrm{wt} \%$ ), acetylene black (10 wt $\%)$ and polytetrafluoroethylene (5 wt\%) binder with ethanol to form a slurry and then spreading the slurry onto a slice of nickel foam with a coating area of $1 \mathrm{~cm}^{2}$. 
Afterwards, the slices were dried at $110{ }^{\circ} \mathrm{C}$ for 6 hours in a vacuum oven and then pressed under a pressure of $6 \mathrm{MPa}$ to completely adhere the electrode materials. The active material of each electrode sheet had a mass loading of about $1.2 \mathrm{mg} \mathrm{cm}^{-2}$. Symmetric two-electrode supercapacitors with $6 \mathrm{M} \mathrm{KOH}$ aqueous electrolyte were constructed from two analogous electrodes on nickel foam separated by a piece of polypropylene membrane, which were wrapped with Teflon tape to form a sandwich structure. The active material of each electrode sheet had a mass loading of approximately $2.0 \mathrm{mg} \mathrm{cm}^{-2}$.

Symmetric two-electrode supercapacitors with $1 \mathrm{M}$ TEABF4/AN organic electrolyte were constructed from stainless-steel coin cells (2032-type). The electrode materials were prepared by mixing CsCNBs $(80 \mathrm{wt} \%)$, acetylene black $(10 \mathrm{wt} \%)$ and the polytetrafluoroethylene (10 wt $\%$ ) binder with ethanol to form a slurry, and then dried electrodes on aluminium foil wafers (15 mm dia.) were symmetrically assembled with a single-layer Celgard-2500 membrane as the separator in a glovebox filled with argon. The mass loading of the active material per electrode wafer was about $2.0 \mathrm{mg} \mathrm{cm}^{-2}$.

The electrochemical properties, including the cyclic voltammetry (CV), galvanostatic chargedischarge (GCD), electrochemical impedance spectroscopy (EIS) and cyclic stability characteristic, were measured by using an electrochemical workstation (VMP-300).

The specific capacitance of the electrodes was calculated from the CV data according to the following equation:

$$
C_{\mathrm{s}}=\frac{1}{2 m v \times \Delta V} \int I \mathrm{~d} V .
$$

Here, $\mathrm{Cs}\left(\mathrm{F} \mathrm{g} \mathrm{g}^{-1}\right)$ is the specific capacitance of the electrodes, I (A) is the discharge current, $\mathrm{V}$ $(\mathrm{V})$ is the potential, $\mathrm{m}(\mathrm{g})$ is the mass loading of active materials, $v\left(\mathrm{~V} \mathrm{~s}^{-1}\right)$ is the scanning rate, $\Delta \mathrm{V}(\mathrm{V})$ is the scanning potential range, and the factor 2 is attributed to the area containing both the forward and reverse scans. 
The specific capacitance of an electrode can be calculated from the GCD data according to the following equation:

$$
C_{\mathrm{m}}=\frac{I \times \Delta t}{m \times \Delta V} \text {. }
$$

Here, $\mathrm{Cm}\left(\mathrm{F} \mathrm{g} \mathrm{g}^{-1}\right), \mathrm{I}(\mathrm{A}), \Delta \mathrm{t}(\mathrm{s}), \mathrm{m}(\mathrm{g})$, and $\Delta \mathrm{V}(\mathrm{V})$ are the specific capacitance, the discharge current, the discharge time, the mass loading of active materials and the discharge potential range of the GCD curve, respectively.

The energy density $\mathrm{E}\left(\mathrm{W} \mathrm{h} \mathrm{kg}^{-1}\right)$ is calculated according to the following equation:

$$
E=\frac{1}{2} C_{\mathrm{m}} \times \Delta V^{2} \times \frac{1}{3.6}
$$

The power density $\mathrm{P}\left(\mathrm{W} \mathrm{kg}^{-1}\right)$ is computed based on the following equation:

$P=3600 \frac{E}{\Delta t}$

where $\mathrm{Cm}\left(\mathrm{F} \mathrm{g}^{-1}\right)$ is the specific capacitance, I (A) is the discharge current, $\mathrm{m}(\mathrm{g})$ is the mass loading of active materials, $\Delta \mathrm{V}(\mathrm{V})$ is the discharge potential range, and $\Delta \mathrm{t}(\mathrm{s})$ is the discharge time.

\section{Results and discussion}

\subsection{Material characterization}

The FESEM images of samples CsCNBs*3, CsCNBs*4, CsCNBs*5 and CsCNBs-950-40 are shown in Fig. 1. Clews $(10-30 \mu \mathrm{m})$ formed from numerous intertwined nanobelts are clearly visible in Fig. 1a, c, e and g. With the increase of the $\mathrm{KOH} / \mathrm{C}$ mass ratio, the average diameter of the clews decreases. As seen from Fig. $1 b, d, f$ and $h$, the typical narrow and thin nanobelts randomly intertwine with each other, generating a three-dimensional open channel and a conductive network structure. $\mathrm{KOH}$ and $\mathrm{CO}_{2}$ activation does not substantially destroy the structure of the nanobelts. ${ }^{23}$ 

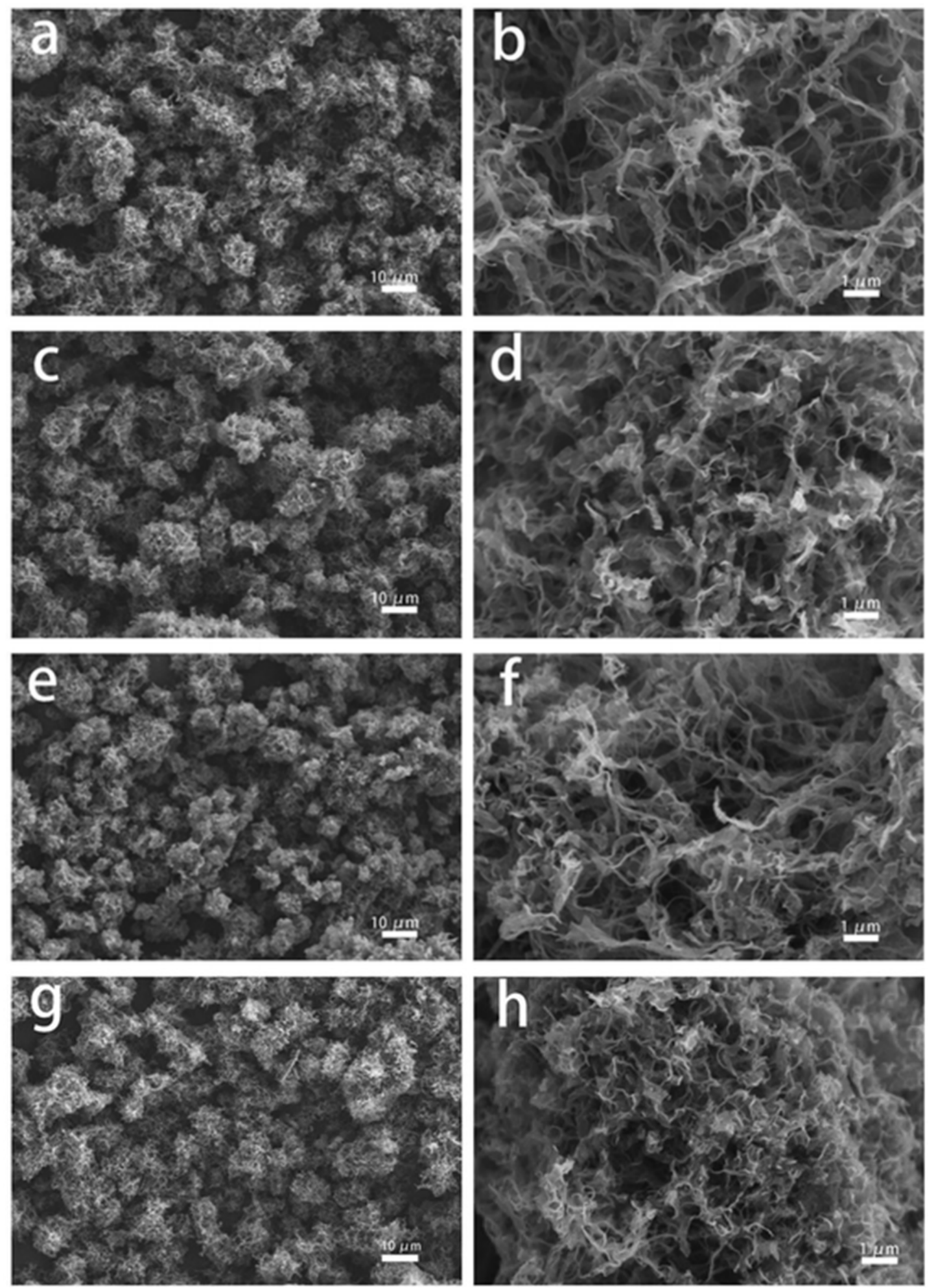

Fig. 1 FESEM images of (a, b) CsCNBs*3, (c, d) CsCNBs*4, (e, f) CsCNBs*5, and (g, h) CsCNBs-950-40.

The HRTEM images of samples CsCNBs*3, CsCNBs*4, CsCNBs*5 and CsCNBs-950-40 are shown in Fig. 2. Fig. 2a, c, e and g display narrow and thin nanobelts, consistent with the 
FESEM images. In Fig. 2b, d, f and h, a large number of disordered black stripes can be seen, which correspond to the lattice fringes of the (002) plane of amorphous carbon. A high density of white spots that characterize nanopores can also be seen. ${ }^{14,23}$ The fine structures of all samples are further explored by high-resolution TEM (refer to Fig. S1 $\dagger$ ), further revealing the presence of large amounts of amorphous carbon and nanopores.
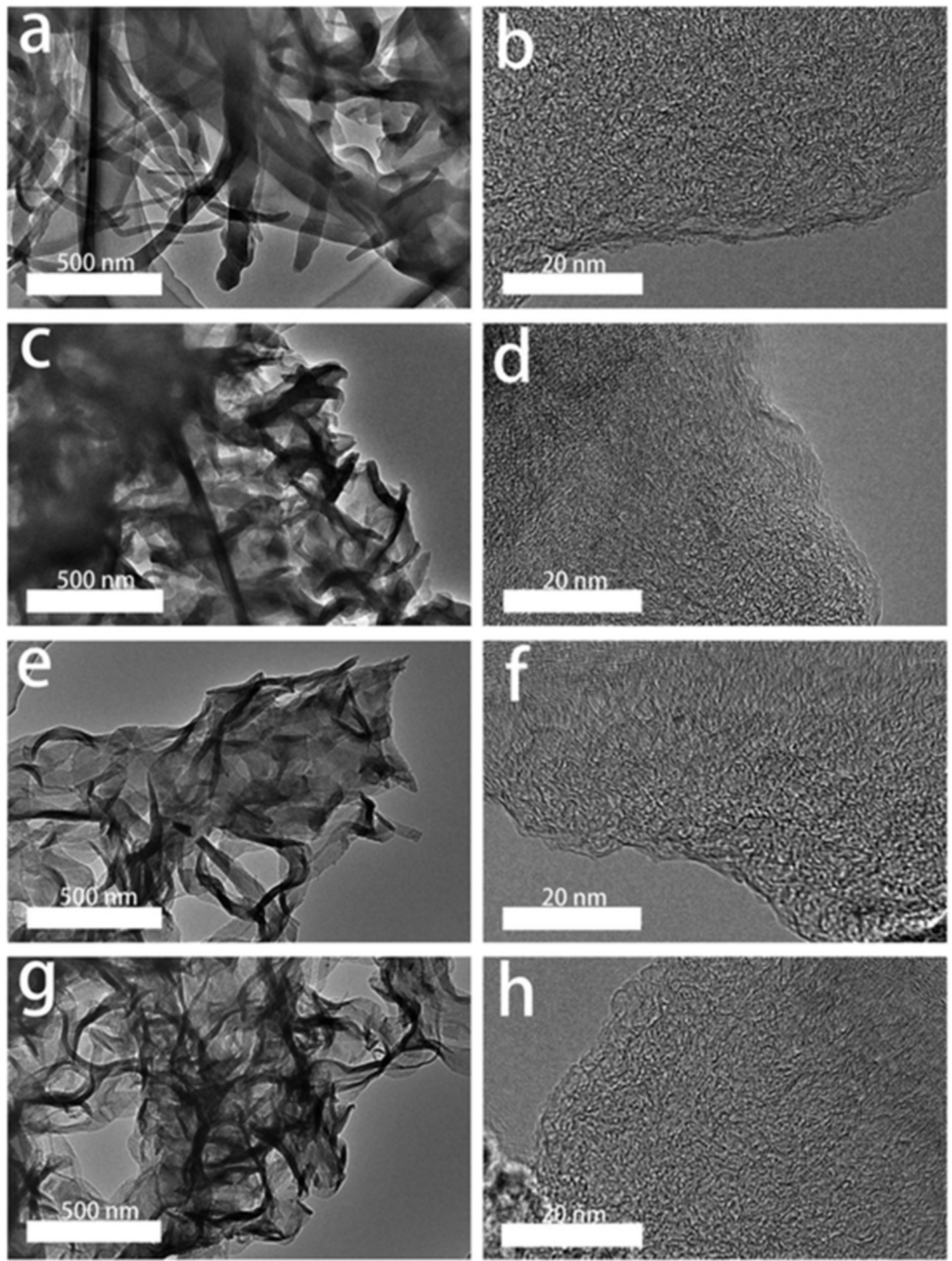
Fig. 2 HRTEM images of (a, b) CsCNBs*3, (c, d) CsCNBs*4, (e, f) CsCNBs*5, and (g, h) CsCNBs-950-40.

Fig. 3a shows the XRD patterns of four activated carbon samples. All the XRD patterns contain two primary broad diffraction peaks consisting of $\left(\begin{array}{lll}0 & 0 & 2\end{array}\right)$ and $\left(\begin{array}{lll}1 & 0 & 0\end{array}\right)$ planes that match graphitic carbon. The peaks at $2 \theta$ values of $20-25^{\circ}$, attributed to the $\left(\begin{array}{lll}0 & 0 & 2\end{array}\right)$ reflection of the graphitictype lattice, are wider and have lower intensities than the two primary peaks, demonstrating the characteristics of amorphous carbon. ${ }^{25,26}$ The other peaks at approximately $43^{\circ}$ are consistent with the $\left(\begin{array}{lll}1 & 0 & 0\end{array}\right)$ reflection, indicating a low degree of development of the graphitic structure. Fig. $3 \mathrm{~b}$ shows that all four samples possess two typical carbon characteristic peaks at $1350 \mathrm{~cm}^{-1}$ (D band) and $1586 \mathrm{~cm}-1$ (G band) in the Raman spectra. The $\mathrm{G}$ band is generated by the stretching movement of all the sp2 atoms in the carbocycles or long chains. The $\mathrm{D}$ band is caused by defects and disorder in the structure. ${ }^{27-31}$ As the $\mathrm{KOH} / \mathrm{C}$ mass ratio increases from 3 to 4 , the intensity ratio (ID/IG) also increases from 0.95 to 0.97 . In contrast, the ID/IG of sample CsCNBs*5 decreases to 0.92 . The $\mathrm{KOH}$ activation of sample CsCNBs*5, although leading to higher amounts of defects, can also react with more graphitized regions, resulting in excessive ablation of the activated carbon and even collapse of the formed pores. Simultaneously, the result that CsCNBs*5 has a smaller specific surface area and pore volume than CsCNBs*4 is also shown in Table 1 . So, the $\mathrm{KOH}$ activation is excessive for sample CsCNBs*5. Furthermore, the ratios are significantly lower than that of commercial activated carbon (1.92), which can be favourable for achieving a high conductivity. ${ }^{25}$ Compared to the sample CsCNBs-950-40, the samples prepared by $\mathrm{KOH}$ activation display an obvious secondorder band (2D) at $2700 \mathrm{~cm}^{-1}$, which is attributed to the existence of ordered carbon structures. 

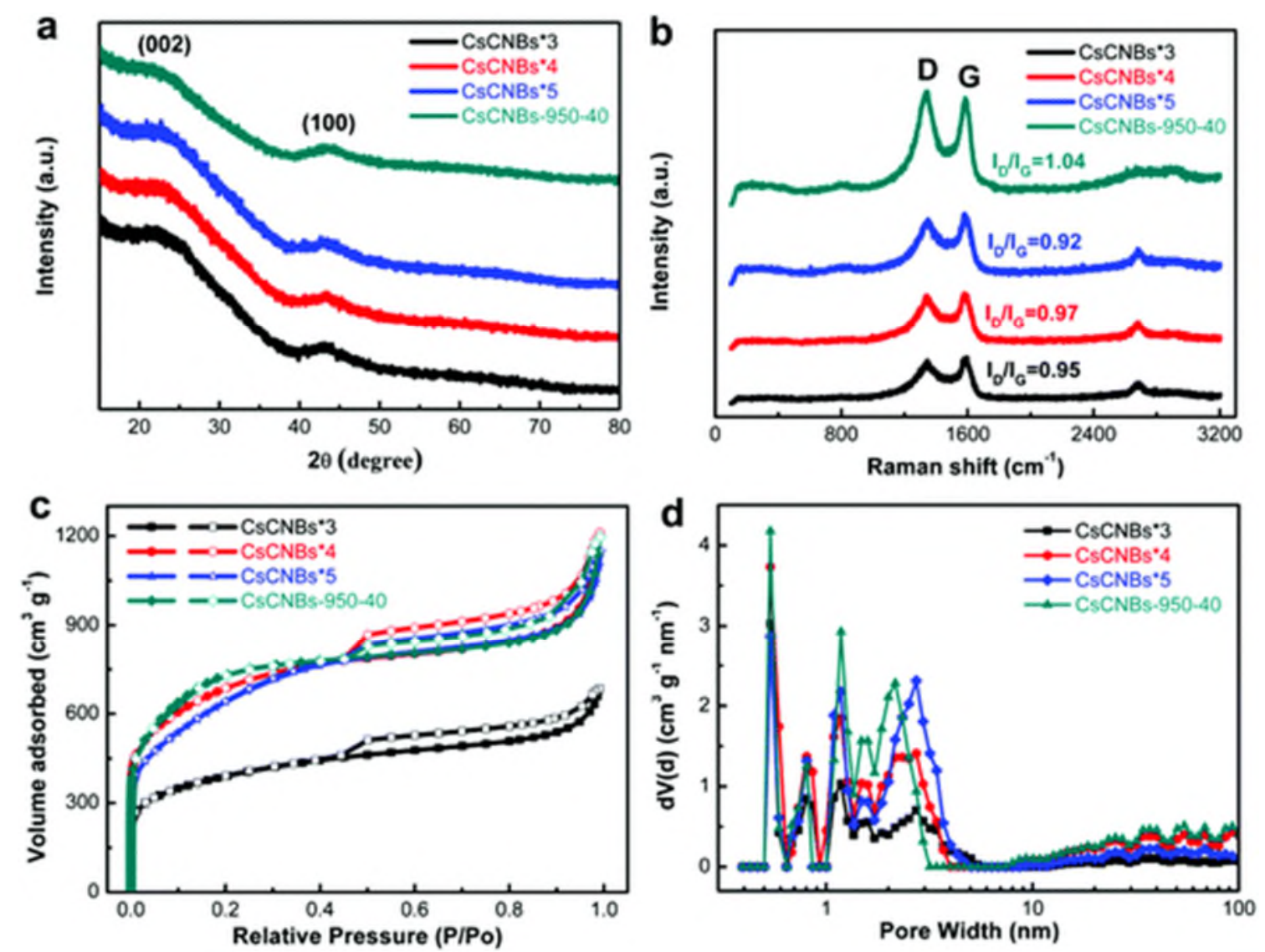

Fig. 3 (a) XRD patterns and (b) Raman spectra of the four activated carbon samples; (c) nitrogen adsorption-desorption isotherms and (d) PSD curves of the four activated carbon samples, calculated from the nitrogen adsorption isotherms using the DFT method.

Table 1 Textural parameters of the activated carbon samples

\section{Vtotal}

SBET SDFT (cm3 Vmicro Vmeso Daverage Carbon

Sample $\quad(\mathrm{m} 2 \mathrm{~g}-1)(\mathrm{m} 2 \mathrm{~g}-1) \mathrm{g}-1) \quad(\mathrm{cm} 3 \mathrm{~g}-1)(\mathrm{cm} 3 \mathrm{~g}-1)(\mathrm{nm}) \quad$ yield $(\%)$

\begin{tabular}{lccccccc}
\hline CsCNBs*3 & 1300 & 1139 & 0.60 & 0.37 & 0.20 & 3.14 & 46 \\
CsCNBs*4 & 2291 & 1889 & 1.29 & 0.67 & 0.45 & 3.11 & 39 \\
CsCNBs*5 & 2240 & 1609 & 1.13 & 0.52 & 0.53 & 3.04 & 32 \\
CsCNBs- & 2623 & 1836 & 1.37 & 0.74 & 0.44 & 2.69 & 23
\end{tabular}

$950-40$ 
Fig. 3c shows the nitrogen-adsorption isotherms of four activated carbon samples. According to the classification of physical adsorption-desorption isotherms proposed by the International Union of Pure and Applied Chemistry (IUPAC), the isotherms of four activated carbon samples exhibit type I/IV characteristics, indicating the existence of numerous micropores and mesopores. In the low relative pressure region (less than 0.01 ), the extent of nitrogen adsorption increases rapidly, indicating that activation produces a large number of micropores. The extent of nitrogen adsorption gradually increases with increasing relative pressure. When the relative pressure is greater than 0.45 , an obvious hysteresis loop is observed, indicating the presence of a large number of mesopores. At relative pressures above 0.95 , the extent of nitrogen adsorption rises rapidly, indicating the existence of macropores. ${ }^{12,23,26,32-35}$ Fig. $3 d$ shows the pore size distribution (PSD) curves of the four activated carbon samples calculated from the nitrogen adsorption isotherms using the DFT method. Five sharp peaks centred at $0.54,0.80$, 1.17, 1.48 and $2.73 \mathrm{~nm}$ are found in all PSD curves. In Table 1, the average pore sizes of samples CsCNBs*3, CsCNBs*4, CsCNBs*5 and CsCNBs-950-40 decrease to $3.14 \mathrm{~nm}, 3.11$ $\mathrm{nm}, 3.04 \mathrm{~nm}$ and $2.69 \mathrm{~nm}$, respectively. After $\mathrm{KOH}$ activation, the BET surface area (SBET) values of samples CsCNBs*3, CsCNBs*4 and CsCNBs*5 are 1300, 2291 and $2240 \mathrm{~m} 2 \mathrm{~g}^{-1}$, respectively. At a $\mathrm{KOH} / \mathrm{C}$ mass ratio of 5 , SBET is slightly reduced, indicating that excess $\mathrm{KOH}$ is not favourable for producing a high specific surface area. As the BET model may be unreliable for microporous carbons,${ }^{36}$ the specific surface areas calculated using the DFT approach (SDFT) are shown in Table 1 . Sample CsCNBs*4 clearly has a very high SDFT of $1889 \mathrm{~m}^{2} \mathrm{~g}^{-1}$, which is much larger than the SDFT values of the other samples produced by $\mathrm{KOH}$ activation. Particularly, CsCNBs*4 and CsCNBs-950-40 have excellent features, containing higher SDFT values, pore volumes and distributions of micropores and mesopores than the other samples. Note that the carbon yield of sample CsCNBs*4 is 1.7 times that of sample CsCNBs-950-40. In addition, the inherent three-dimensional conductive network 
structure of the CsCNB samples may guarantee high accessibility and utilization of the surface for ion adsorption/desorption. Furthermore, under the action of the three-dimensional conductive network structure, the direct exposure of the highly porous nanobelts to the electrolyte may efficiently shorten the transport pathways and lower the resistance for ion diffusion. These textural characteristics may endow the CsCNBs with excellent potential for application in high-performance supercapacitors. ${ }^{14,37}$

Fig. 4 and Fig. S2† show the XPS survey spectra of the four activated carbon materials, which contain two elements, carbon and oxygen. The carbon and oxygen contents are individually calculated from the peak areas of the $\mathrm{C} 1 \mathrm{~s}$ and $\mathrm{O}$ 1s peaks, and the results agree well with those from elemental analysis (Table $\mathrm{S} 1 \dagger$ ). The $\mathrm{C} 1 \mathrm{~s}$ spectra of the three samples prepared by $\mathrm{KOH}$ activation (Fig. 4c, S2c and S2d $\dagger$ ) clearly exhibit four individual component peaks corresponding to $\mathrm{C}-\mathrm{C} / \mathrm{C}=\mathrm{C}(\sim 284.3 \mathrm{eV}), \mathrm{C}-\mathrm{O}(\sim 285.9 \mathrm{eV}), \mathrm{C}=\mathrm{O}(\sim 287.6 \mathrm{eV})$, and $\mathrm{O}-\mathrm{C}=\mathrm{O}$ species $(\sim 289.7 \mathrm{eV})$. The O 1s spectra (Fig. 4e, S1e and S1f $\dagger$ ) are resolved into four oxygenbased groups: $\mathrm{C}=\mathrm{O}(\sim 531.0 \mathrm{eV}), \mathrm{C}-\mathrm{O}(\sim 532.5 \mathrm{eV}), \mathrm{H} 2 \mathrm{O}(\sim 534.3 \mathrm{eV})$, and $\mathrm{C}-\mathrm{OH} / \mathrm{C}-\mathrm{O}-\mathrm{C}$ ( 535.9 eV). However, sample CsCNBs-950-40 lacks the $\mathrm{O}-\mathrm{C}=\mathrm{O}$ peak $(\sim 289.7 \mathrm{eV})$ in the $\mathrm{C}$ 1s spectrum (Fig. 4d) and the $\mathrm{C}-\mathrm{OH} / \mathrm{C}-\mathrm{O}-\mathrm{C}$ peak $(\sim 535.9 \mathrm{eV})$ in the $\mathrm{O} 1 \mathrm{~s}$ spectrum (Fig. 4f). ${ }^{38-41}$ In addition, significantly fewer O-containing functional groups are present in sample CsCNBs-950-40 than in the others, indicating its low surface energy and poor hydrophilicity.4 The poor hydrophilicity of CsCNBs-950-40 is proved by a simple hydrophilic test in Fig. S3. $\dagger$ The compatibility between the electrode surface and the electrolyte has a certain impact on the capacitance of the activated carbons, which means that the capacitive performance of the three samples prepared by $\mathrm{KOH}$ activation may be distinctly better than that of sample CsCNBs$950-40$. 

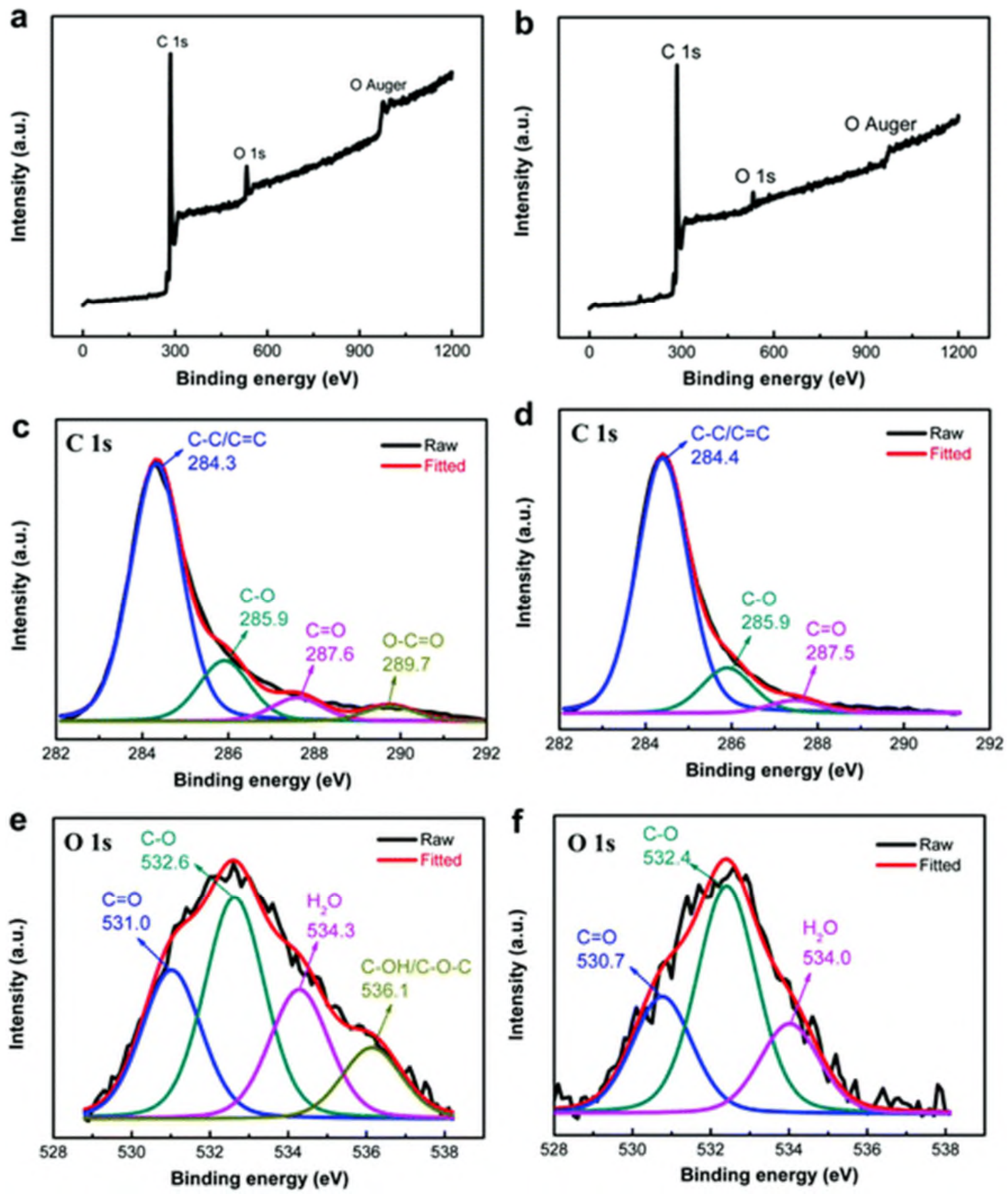

4 XPS results of the CsCNBs*4 sample: (a) XPS survey, (c) C 1s spectrum, and (e) O $1 \mathrm{~s}$ spectrum; XPS results of the CsCNBs-950-40 sample: (b) XPS survey, (d) C 1s spectrum, and (f) $\mathrm{O} 1 \mathrm{~s}$ spectrum. 


\subsection{Electrochemical performance in a three-electrode system}

The performance of samples CsCNBs*3, CsCNBs*4, CsCNBs*5 and CsCNBs-950-40 is first investigated in a three-electrode system using $6 \mathrm{M} \mathrm{KOH}$ as the electrolyte. $\mathrm{CV}$ measurements are performed over the potential range from -1 to $0 \mathrm{~V}$ at various scanning rates from 5 to 200 $\mathrm{mV} \mathrm{s}^{-1} \cdot{ }^{42,43}$ Fig. 5a shows the $\mathrm{CV}$ curves of the four samples obtained at a scanning rate of 10 $\mathrm{mV} \mathrm{s}^{-1}$. All the $\mathrm{CV}$ curves display a symmetric and rectangular shape, which fits the features of supercapacitors and further indicates that the samples exhibit good electrochemical performance. Fig. $5 \mathrm{~b}$ shows the $\mathrm{CV}$ curves of sample $\mathrm{CsCNBs} * 4$ under various scanning rates from 5 to $200 \mathrm{mV} \mathrm{s}^{-1}$. The $\mathrm{CV}$ curve remains symmetric with a quasi-rectangular shape, even at an ultrahigh scanning rate of $200 \mathrm{mV} \mathrm{s}^{-1}$, indicating the excellent electrical conductivity, reversibility and capacitance characteristics of this material. Fig. $\mathrm{S} 4 \dagger$ indicates that the contribution of foam nickel is far less than the active material in the cyclic voltammetry testing. Therefore, the capacitance generated by the foamed nickel in the electrochemical test is negligible. Fig. 5c shows the corresponding specific capacitances (Cs) calculated by using eqn (1). The three samples prepared by $\mathrm{KOH}$ activation have superior specific capacitances, especially sample CsCNBs*4, which displays a superhigh specific capacitance of $332.5 \mathrm{~F} \mathrm{~g}^{-1}$ and an ultrahigh specific capacitance retention ratio of $85.9 \%$ at $200 \mathrm{mV} \mathrm{s}^{-1}$, clearly supporting our hypothesis that the three-dimensional conductive network structure is beneficial for improving the electrochemical performance. ${ }^{44-46}$ 

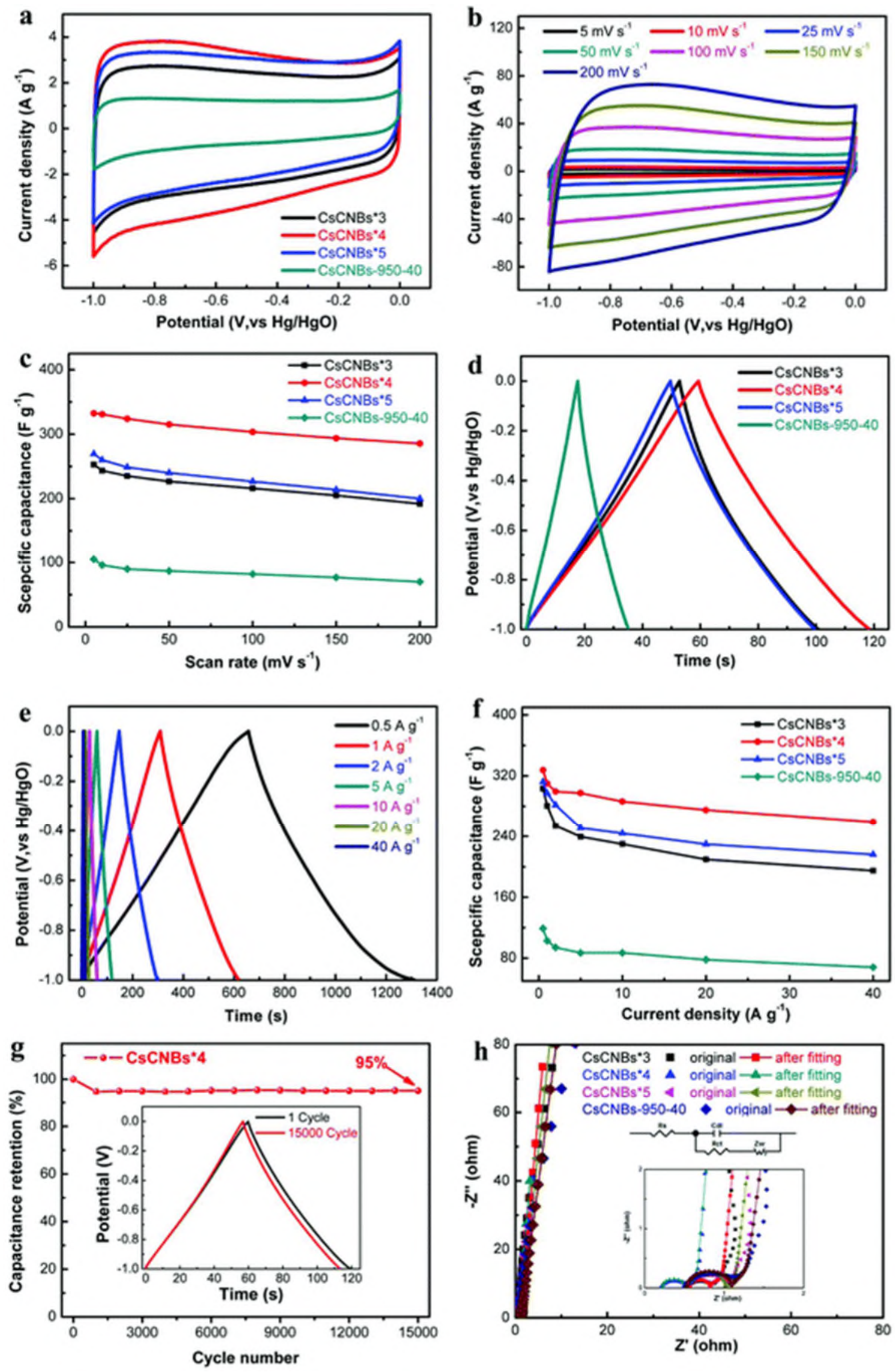
Fig. $5 \mathrm{CV}$ curves (a) of the four electrodes at a potential scanning rate of $10 \mathrm{mV} \mathrm{s}^{-1}$ and (b) of CsCNBs*4 at various scanning rates ranging from 5 to $200 \mathrm{mV} \mathrm{s}^{-1}$; (c) specific capacitances of the four electrodes at various potential scanning rates; GCD curves (d) of the four electrodes at a current density of $5 \mathrm{~A} \mathrm{~g} \mathrm{~g}^{-1}$ and (e) of $\mathrm{CsCNBs}^{*} 4$ at different current densities ranging from $0.5 \mathrm{~A} \mathrm{~g}^{-1}$ to $40 \mathrm{~A} \mathrm{~g}^{-1}$; (f) specific capacitances of the four electrodes at various current densities; (g) cycling stability of the CsCNBs*4 electrode at a current density of $5 \mathrm{~A}$ $\mathrm{g}^{-1}$ over 15000 cycles; (h) Nyquist plots and fitting Nyquist plots of the four electrodes in a three-electrode system using $6 \mathrm{M} \mathrm{KOH}$ as the electrolyte. The inset shows the enlarged view of the high-frequency region and the electrical equivalent circuit for fitting EIS.

To further research the electrochemical performance of the four samples, GCD measurements are performed in the potential range from -1 to $0 \mathrm{~V}$ in $6 \mathrm{M} \mathrm{KOH}$ at current densities from 0.5 to $40 \mathrm{~A} \mathrm{~g}^{-1}$. The perfectly isosceles triangular GCD curves of the four samples at a current density of $5 \mathrm{~A} \mathrm{~g} \mathrm{~g}^{-1}$ shown in Fig. 5d are indicative of highly reversible and ideal supercapacitor behaviour and high charge-discharge efficiency. ${ }^{47}$ The discharging time of sample CsCNBs*4 is significantly longer than those of the others, indicating that sample CsCNBs*4 possesses a much larger charge storage ability, which is consistent with the results of the CV tests. This feature is also proven by the highly symmetric and linear GCD curves of sample CsCNBs*4 at different current densities, shown in Fig. 5e. ${ }^{48}$ The corresponding specific capacitances $(\mathrm{Cm})$ calculated by using eqn. (2) are shown in Fig. 5f. Sample CsCNBs*4 displays a maximum specific capacitance of $327.5 \mathrm{~F} \mathrm{~g} \mathrm{~g}^{-1}$ at $0.5 \mathrm{~A} \mathrm{~g} \mathrm{~g}^{-1}$, better than nitrogen and oxygen co-doped clews of carbon nanobelts (NCNBs-60, $282 \mathrm{~F} \mathrm{~g}^{-1}$ at $\left.0.25 \mathrm{~A} \mathrm{~g} \mathrm{~g}^{-1}\right){ }^{49} \mathrm{In}$ addition, sample CsCNBs*4 still has a upper specific capacitance of $260 \mathrm{~F} \mathrm{~g} \mathrm{~g}^{-1}$ even at an ultrahigh current density of $40 \mathrm{~A} \mathrm{~g} \mathrm{~g}^{-1}$, further proving that the three-dimensional conductive network structure of sample $\mathrm{CsCNBs}^{*} 4$ is extremely beneficial for ion-migration. Due to the lack of oxygen- 
containing surface functional groups and the poor hydrophilicity of the surface, sample CsCNBs-950-40 displays a low specific capacitance of $120 \mathrm{~F} \mathrm{~g}^{-1}$ at $0.5 \mathrm{~A} \mathrm{~g}^{-1}$. In Fig. S5, $\dagger$ the coulombic efficiencies of the four samples are close to $100 \%$, indicating good chargedischarge efficiency.

Cycling stability is an important factor for evaluating the potential of a material for practical applications in supercapacitors. ${ }^{50}$ Fig. $5 \mathrm{~g}$ shows the GCD cycling measurements of the CsCNBs*4 sample at a constant current density of $5 \mathrm{~A} \mathrm{~g}^{-1}$ for 15000 cycles. After 15000 cycles, the sample still retains $95 \%$ of the initial capacitance. The isosceles-triangular and symmetric GCD curves (inset in Fig. 5g) are also maintained during the cycling tests, indicating the excellent long-term cycling stability. In summary, sample CsCNBs*4 possesses a threedimensional conductive network structure that facilitates fast ion transfer and provides a large specific surface area and pore volume that contain more surface-active sites for storing energy. EIS is used to further investigate the electrochemical behaviour of the supercapacitor. EIS measurements are made in the frequency range from $0.01 \mathrm{~Hz}$ to $100 \mathrm{kHz}$ with a signal amplitude of $5 \mathrm{mV} .{ }^{51}$ Fig. $5 \mathrm{~h}$ shows the Nyquist plot and fitting Nyquist plots of samples CsCNBs*3, CsCNBs*4, CsCNBs*5 and CsCNBs-950-40. Every sample has an obvious semicircle in the high-frequency region which represents the charge transfer resistance of the supercapacitors, and a vertical line in the low-frequency range. ${ }^{52}$ From the inset of Fig. $5 \mathrm{~h}$, the ohmic resistances (Rs) of samples CsCNBs*3, CsCNBs*4, CsCNBs*5 and CsCNBs-950-40 are $0.56 \Omega, 0.22 \Omega, 0.52 \Omega$ and $0.53 \Omega$, respectively. The charge transfer resistances (Rct) of samples CsCNBs*3, CsCNBs*4, CsCNBs*5 and CsCNBs-950-40 are $0.27 \Omega, 0.26 \Omega, 0.51 \Omega$ and $0.57 \Omega$, respectively. Sample $\mathrm{CsCNBs}^{*} 4$ has minimal Rs and Rct, indicating a low system resistance and high charge-transfer rate. In the low-frequency range, all samples have an almost vertical line that represents the ion diffusion resistance $(\mathrm{Zw})$, which indicates a perfect capacitive behaviour. ${ }^{17,25}$ 
In comparison with the reported activated carbon materials prepared by $\mathrm{KOH}$ activation (Table 2), sample $\mathrm{CsCNBs}^{*} 4$ displays a superior specific capacitance of $327.5 \mathrm{~F} \mathrm{~g}^{-1}$ at $0.5 \mathrm{~A} \mathrm{~g}^{-1}$ and a ultrahigh specific capacitance retention ratio of $77.8 \%$ at $40 \mathrm{~A} \mathrm{~g}^{-1}$. Note that the high SDFT, large number of micropores and mesopores, excellent hydrophilicity, and the inherent threedimensional conductive network structure of sample $\mathrm{CsCNBs} * 4$ guarantee a highly accessible and active surface area for ion adsorption/desorption.

Table 2 Electrochemical properties of reported carbon-based supercapacitors

\begin{tabular}{|c|c|c|c|c|c|c|}
\hline \multirow[b]{2}{*}{ Electrode materials } & \multirow{2}{*}{$\begin{array}{l}\text { Test } \\
\text { systema }\end{array}$} & \multicolumn{2}{|c|}{$\mathrm{Sb} \quad\left(\mathrm{m}^{2}\right.$} & \multirow[b]{2}{*}{$\mathrm{Tc}$} & \multicolumn{2}{|c|}{$\mathrm{Cd} \quad(\mathrm{F}$} \\
\hline & & $\left.\mathrm{g}^{-1}\right)$ & Electrolyte & & $\left.\mathrm{g}^{-1}\right)$ & Ref. \\
\hline \multirow[t]{2}{*}{ TEA/rGO } & $2 \mathrm{E}$ & 527.8 & TEABF4/AN & $10 \mathrm{~m}$ & $\mathrm{aV} 118$ & 4 \\
\hline & & & & $\mathrm{s}^{-1}$ & & \\
\hline Polypyrrole & $3 \mathrm{E}$ & 2870 & $6 \mathrm{M} \mathrm{KOH}$ & 0.5 & A 318.2 & 11 \\
\hline microsheets & & & & $\mathrm{g}^{-1}$ & & \\
\hline Alkali lignin & $3 \mathrm{E}$ & - & $6 \mathrm{M} \mathrm{KOH}$ & $1 \mathrm{Ag}^{-1}$ & -1316 & 29 \\
\hline $\mathrm{PR} / \mathrm{PE}$ & $2 \mathrm{E}$ & 1520 & Et4NBF4/AN & $1 \mathrm{Ag}^{-1}$ & -187 & 30 \\
\hline \multirow[t]{2}{*}{ MOF-5 } & $3 \mathrm{E}$ & 2222 & $6 \mathrm{M} \mathrm{KOH}$ & 0.25 & A 271 & 32 \\
\hline & & & & $\mathrm{g}^{-1}$ & & \\
\hline \multirow[t]{2}{*}{ ZIF-8/PAN } & $3 \mathrm{E}$ & 560 & $6 \mathrm{M} \mathrm{KOH}$ & 0.5 & A 302 & 37 \\
\hline & & & & $\mathrm{g}^{-1}$ & & \\
\hline \multirow[t]{2}{*}{ NCNBs-60 } & $3 \mathrm{E}$ & 2994 & $6 \mathrm{M} \mathrm{KOH}$ & 0.25 & A 282 & 49 \\
\hline & & & & $\mathrm{g}^{-1}$ & & \\
\hline Cellulose acetate & $3 \mathrm{E}$ & 1003.6 & $6 \mathrm{M} \mathrm{KOH}$ & $1 \mathrm{Ag}^{-1}$ & -1242 & 50 \\
\hline Willow catkin & $3 \mathrm{E}$ & 1533 & $6 \mathrm{M} \mathrm{KOH}$ & 0.5 & A 298 & 51 \\
\hline
\end{tabular}


Test $\quad \mathrm{Sb} \quad\left(\mathrm{m}^{2} \quad \mathrm{Cd} \quad(\mathrm{F}\right.$

Electrode materials systema $\left.\quad \mathrm{g}^{-1}\right) \quad$ Electrolyte $\quad$ Tc $\quad \mathrm{g}^{-1}$ ) Ref.

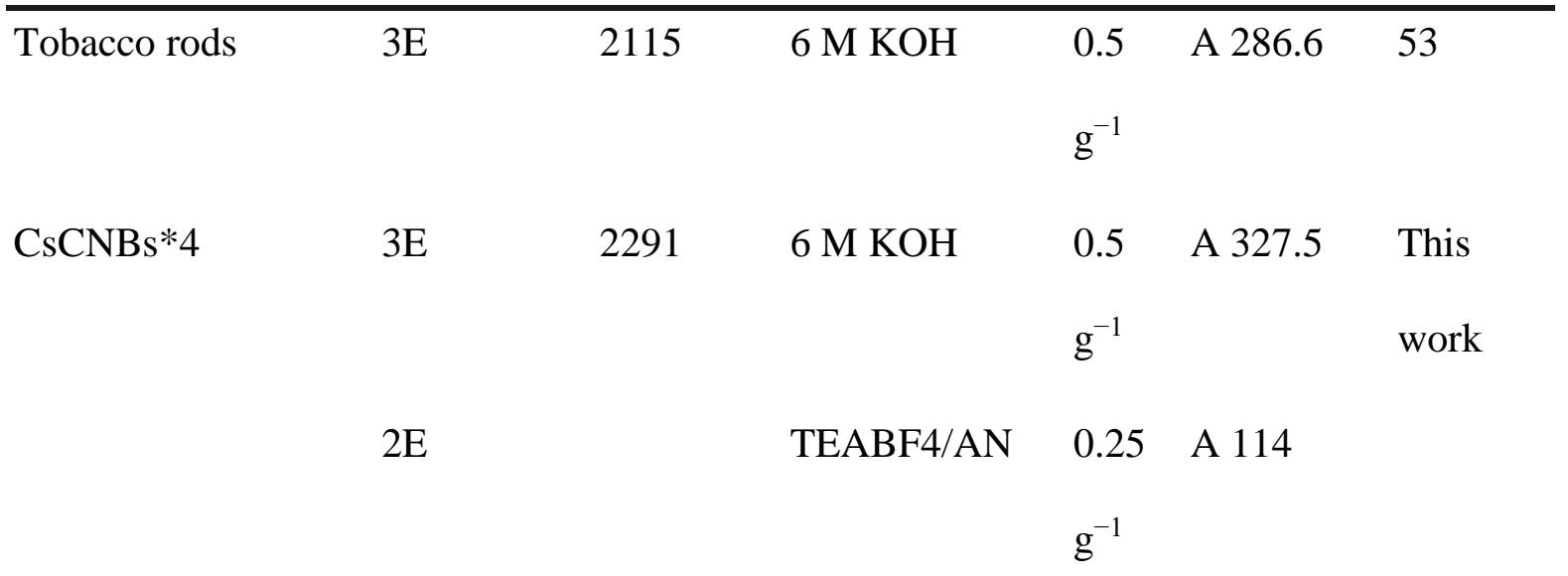

a 2E/3E refers to a two-electrode/three-electrode system test. b BET surface area. c Current density or scanning rate. $\mathrm{d}$ Specific capacitance.

\subsection{Electrochemical performance in a two-electrode system using an aqueous electrolyte}

The electrochemical performance of CsCNBs*4 in a symmetric two-electrode system using 6 $\mathrm{M} \mathrm{KOH}$ as the aqueous electrolyte is examined. Similar to the abovementioned research, the $\mathrm{CV}$ curves of CsCNBs*4 obtained at different scanning rates from 5 to $200 \mathrm{mV} \mathrm{s}^{-1}$ are shown in Fig. 6a. The CV curves clearly exhibit a symmetric and rectangular shape, ${ }^{53}$ which is still maintained for the CV curve obtained at an exceedingly high scanning rate of $200 \mathrm{mV} \mathrm{s}^{-1}$ without drastic changes, indicating the highly efficient ion transport inside the electrodes, the prominent reversibility and the excellent capacitance characteristic. ${ }^{15}$ Fig. S7† shows that the corresponding specific capacitances (Cs) are calculated by using eqn (1). CsCNBs*4 achieves a high specific capacitance of $252 \mathrm{~F} \mathrm{~g}^{-1}$ and specific capacitance retention ratio of $78.0 \%$ at $200 \mathrm{mV} \mathrm{s}^{-1}$. In Fig. 6b, the GCD curves obtained at different current densities reveal nearly symmetric and isosceles triangular shapes, which further indicate the highly reversible chargedischarge behaviour of $\mathrm{CsCNBs} * 4$. The corresponding specific capacitances $(\mathrm{Cm})$ calculated by using eqn (2) are shown in Fig. 6c. The specific capacitance of $\mathrm{CsCNBs}^{*} 4$ is $281.5 \mathrm{~F} \mathrm{~g}^{-1}$ at 
$0.5 \mathrm{~A} \mathrm{~g}^{-1}$. Significantly, the specific capacitance retention ratio is $60 \%$ at a current density of $40 \mathrm{~A} \mathrm{~g}^{-1}$. As shown in Fig. S8, $\uparrow$ the CsCNBs*4 possesses high coulombic efficiencies, indicating excellent reversibility and cycle performance. To assess the potential for practical applications, the GCD cycling stability of CsCNBs*4 is measured at $5 \mathrm{~A} \mathrm{~g}^{-1}$ in Fig. 6d. Meaningfully, nearly identical charge-discharge curves are obtained (inset in Fig. 6d), indicating that this material has excellent electrochemical cycling stability and has intrinsic supercapacitor character. Fig. S9† shows the Nyquist plot and fitting Nyquist plot of sample CsCNBs*4 symmetric supercapacitors in the frequency range from $0.01 \mathrm{~Hz}$ to $100 \mathrm{kHz}$. A low ohmic resistance $(\mathrm{Rs}=0.26 \Omega)$ and charge-transfer resistance $(\mathrm{Rct}=0.23 \Omega)$ mean superior electrochemical performance. ${ }^{54}$
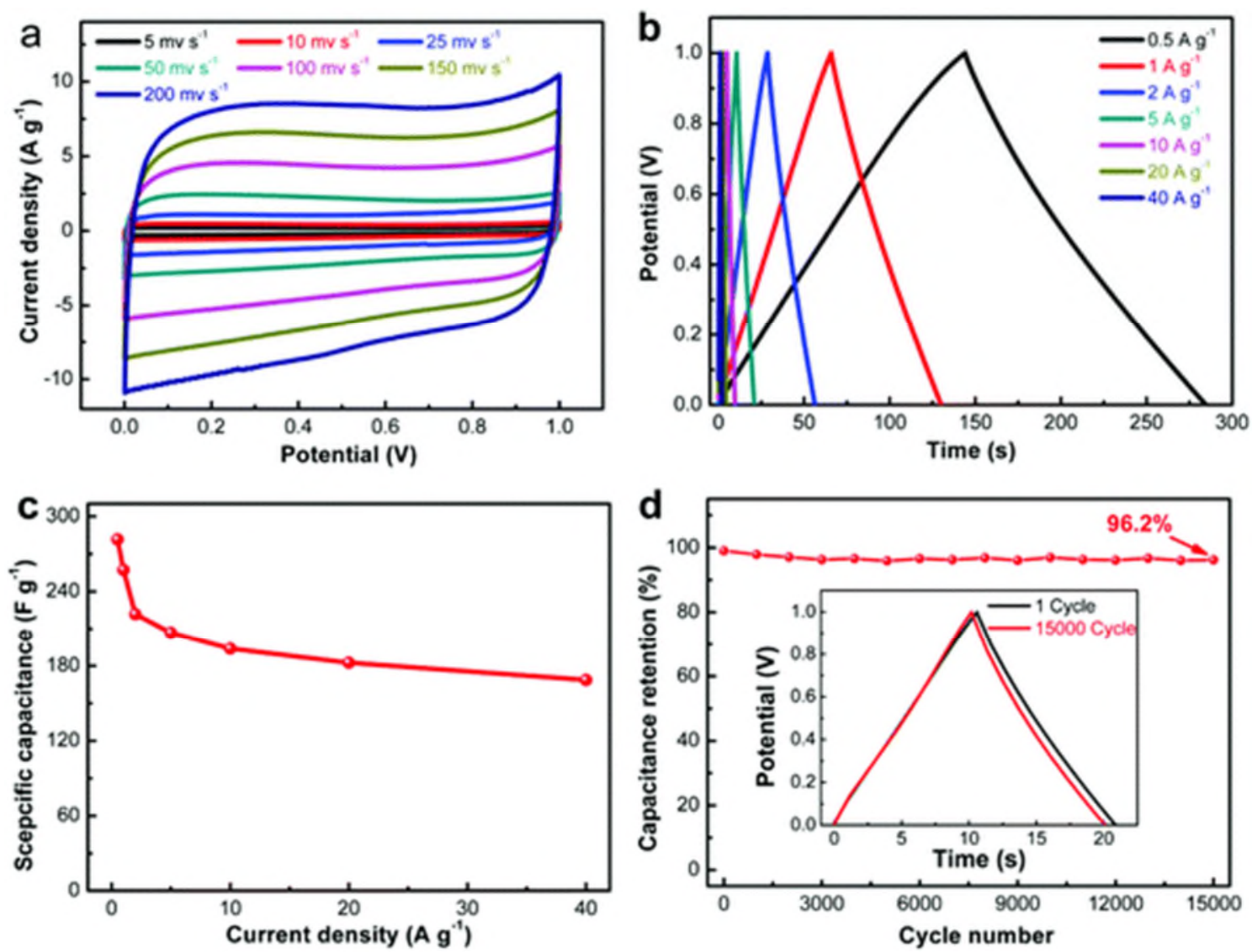

Fig. 6 Electrochemical performance characteristics of CsCNBs*4 measured in a twoelectrode system using $6 \mathrm{M} \mathrm{KOH}$ as the electrolyte. (a) CV curves obtained at various scanning sates ranging from $5 \mathrm{mV} \mathrm{s}^{-1}$ to $200 \mathrm{mV} \mathrm{s}^{-1}$; (b) GCD curves obtained at different 
current densities ranging from $0.5 \mathrm{~A} \mathrm{~g}^{-1}$ to $40 \mathrm{~A} \mathrm{~g}^{-1}$; (c) specific capacitances at various current densities; (d) cycling stability measured at a current density of $5 \mathrm{~A} \mathrm{~g} \mathrm{~g}^{-1}$ over 15000 cycles.

\subsection{Electrochemical performance in a two-electrode system using an organic electrolyte}

In general, the energy density and power density are not only related to the specific capacitance of supercapacitors but also closely related to the stabilized operating voltage. ${ }^{51}$ The electrochemical properties of $\mathrm{CsCNBs}^{*} 4$ in a symmetric two-electrode system using $1 \mathrm{M}$ TEABF4/AN as the organic electrolyte are examined. Fig. 7a shows the CV curves of CsCNBs*4 at a scanning rate of $50 \mathrm{mV} \mathrm{s}^{-1}$ over various voltage windows. The $\mathrm{CV}$ curves, which maintain a symmetric and rectangular shape, exhibit no obvious increase in the anodic current from $1.75 \mathrm{~V}$ to $2.75 \mathrm{~V}$ and then a rapid increase in anodic current at $3.0 \mathrm{~V}$. This result indicates that the two-electrode system using an organic electrolyte is perfectly reversible within the voltage window up to $2.75 \mathrm{~V}$. Fig. $7 \mathrm{~b}$ shows that the $\mathrm{CV}$ curves of CsCNBs*4 display a rectangular shape at different scanning rates from 5 to $200 \mathrm{mV} \mathrm{s}^{-1}$, indicating the ideal rate property of this material. Fig. S10† shows that the corresponding specific capacitances (Cs) are calculated by using eqn (1). CsCNBs*4 displays a high specific capacitance of $116 \mathrm{~F} \mathrm{~g} \mathrm{~g}^{-1}$ and specific capacitance retention ratio of $66.0 \%$ at $200 \mathrm{mV} \mathrm{s}^{-1}$. The GCD curves obtained at various current densities display a nearly symmetric shape (Fig. 7c), revealing its outstanding capacitance characteristics. In Fig. 7d, CsCNBs*4 exhibits high specific capacitances of 114 and $84 \mathrm{~F} \mathrm{~g}^{-1}$ at 0.25 and $20 \mathrm{~A} \mathrm{~g}^{-1}$, respectively. Fig. S11† shows that sample CsCNBs*4 still exhibits excellent coulombic efficiency in the organic electrolyte, indicating that the material has excellent reversibility. In the organic electrolyte, CsCNBs*4 shows a relatively low specific capacitance because the micropores and mesopores cannot completely store the large solvated ions of TEABF4/AN (the ionic radius of TEA+ is $1.3 \mathrm{~nm}$, that of $\mathrm{BF} 4-$ in acetonitrile is $1.16 \mathrm{~nm}$, and that of $\mathrm{K}+$ in water is $0.334 \mathrm{~nm}) .55,56 \mathrm{In}$ addition, 
CsCNBs*4 exhibits an excellent cycling property with 90\% capacitance retention after 15000 cycles at a current density of $5 \mathrm{~A} \mathrm{~g}^{-1}$ as shown in Fig. 7e, and a small IR drop of $0.14 \mathrm{~V}$, inset Fig. 7e. ${ }^{57}$ The Nyquist plot and fitting Nyquist plot of CsCNBs*4 (in the frequency range from $0.01 \mathrm{~Hz}$ to $100 \mathrm{kHz}$, Fig. 7f) also perfectly prove these results. After 15000 cycles, the ohmic resistance (Rs) increases slightly from $2.0 \Omega$ to $2.4 \Omega$, further indicating that this material has ultrahigh cycling stability. The charge-transfer resistance (Rct) increases from $1.0 \Omega$ to $1.8 \Omega$, causing the attenuation of the specific capacity during the cycle. Fig. $7 \mathrm{~g}$ shows the Ragone plots of $\mathrm{CsCNBs}^{*} 4$ in two-electrode systems containing $\mathrm{KOH}$ and TEABF4/AN electrolytes, respectively. The CsCNBs*4-based cell supercapacitor is capable of releasing a high energy density of $9.8 \mathrm{~W} \mathrm{~h} \mathrm{~kg}^{-1}$ at a low power density of $250 \mathrm{~W} \mathrm{~kg}^{-1}$ in $6 \mathrm{M} \mathrm{KOH}$ electrolyte. Even at a very high power density of $21.5 \mathrm{~kW} \mathrm{~kg}^{-1}$, a specific energy of $5.9 \mathrm{~W} \mathrm{~h} \mathrm{~kg}^{-1}$ is still achieved. The wide voltage window of $0-2.75 \mathrm{~V}$ in $1 \mathrm{M}$ TEABF4/AN electrolyte enables higher specific energies of 29.8 and $13.5 \mathrm{~W} \mathrm{~h} \mathrm{~kg}^{-1}$ to be delivered at power densities of 0.35 and $12.3 \mathrm{~kW} \mathrm{~kg}^{-1}$, respectively. Moreover, such a simple cell supercapacitor storage device can power a commercial light-emitting diode (LED), as shown in Fig. $7 \mathrm{~h}$. 

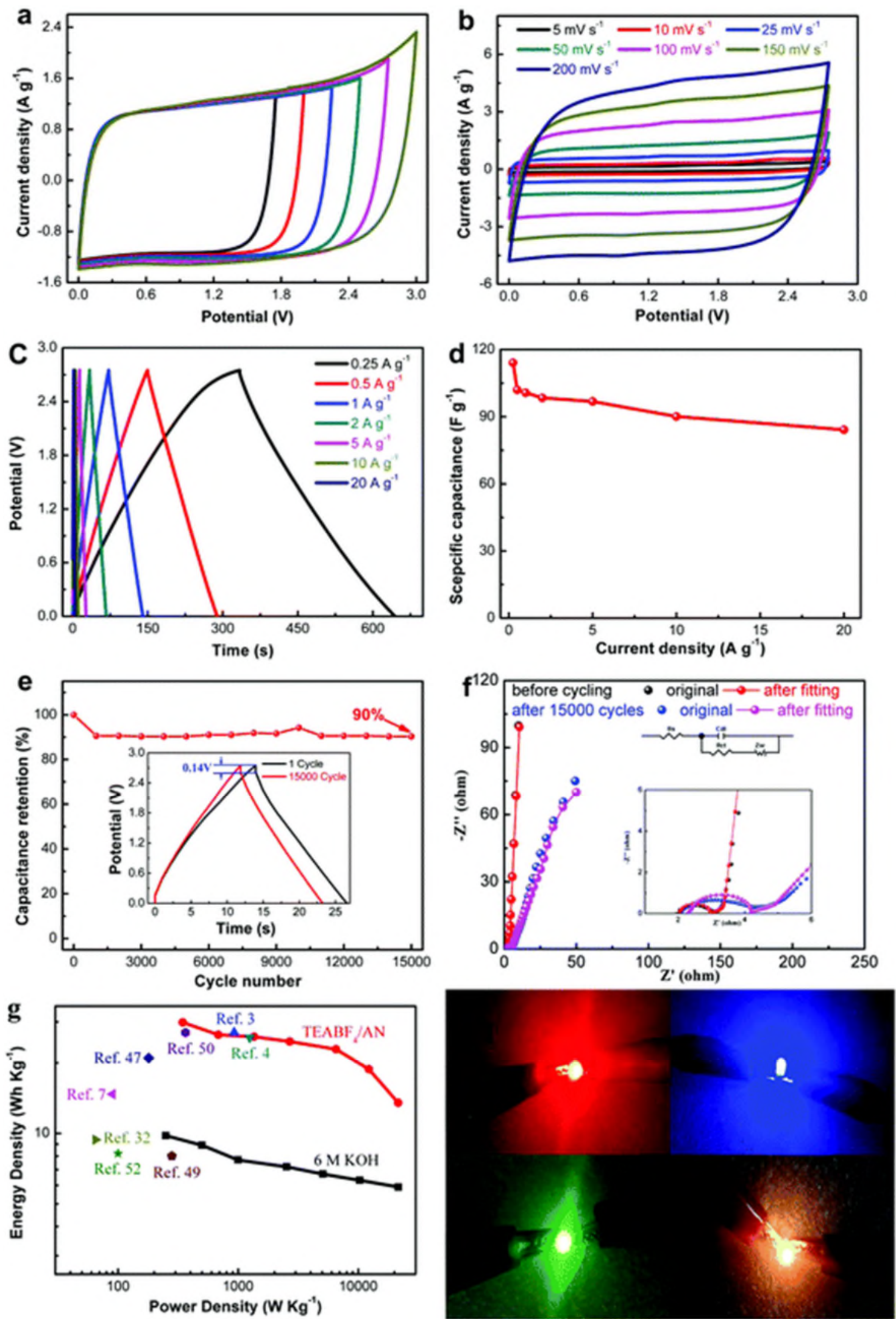

Fig. 7 Electrochemical performance characteristics of $\mathrm{CsCNBs}^{*} 4$ measured in a twoelectrode system using $1 \mathrm{M}$ TEABF4/AN as the electrolyte. (a) CV curves at different 
voltage windows at $50 \mathrm{mV} \mathrm{s}^{-1}$; (b) CV curves at different scanning rates from 5 to $200 \mathrm{mV}$ $\mathrm{s}^{-1}$ in a voltage window from 0 to $2.75 \mathrm{~V}$; (c) charge-discharge curves at different current densities from 0.25 to $20 \mathrm{~A} \mathrm{~g}^{-1}$; (d) specific capacitances at different current densities; (e) cycling stability measured at a current density of $5 \mathrm{~A} \mathrm{~g}^{-1}$ over 15000 cycles; (f) Nyquist plots and fitting Nyquist plots before and after 15000 cycles; (g) Ragone plot of CsCNBs*4, in comparison with reported results; (h) photographs of LEDs powered by the supercapacitor coin cell.

\subsection{The relationship between the structure and the electrochemical performance}

As described above, the CsCNBs are simply achieved by carbonization and further $\mathrm{KOH}$ activation of CsPNBs, and the resultant products possess excellent conductivity and hydrophilicity, ultrahigh specific surface area, and high-density micropores and mesopores while maintaining the original structural integrity. In Fig. 8a and b, the CV curves of CsCNBs*4 display a symmetric and quasi-rectangular shape and a high specific capacitance retention ratio of $72.2 \%$ at $500 \mathrm{mV} \mathrm{s}^{-1}$, indicating that the three-dimensional conductive network structure and hierarchical pores are highly beneficial for achieving efficient ion transport, prominent reversibility and excellent capacitance characteristics. In Fig. 8c, the highperformance capability of $\mathrm{CsCNBs}^{*} 4$ may be ascribed to three factors. First, the highly interconnected three-dimensional conductive network structure possesses completely open channels that facilitate rapid ion transport. Second, the film-like thickness of the nanobelts (approximately $20 \mathrm{~nm}$ ) shortens the ion diffusion pathway at a large electrode/electrolyte interface, producing rapid ion kinetics. Third, the framework of the hierarchically porous nanobelts provides a large ion-accessible surface area, which is conducive to a fast ion adsorption. 

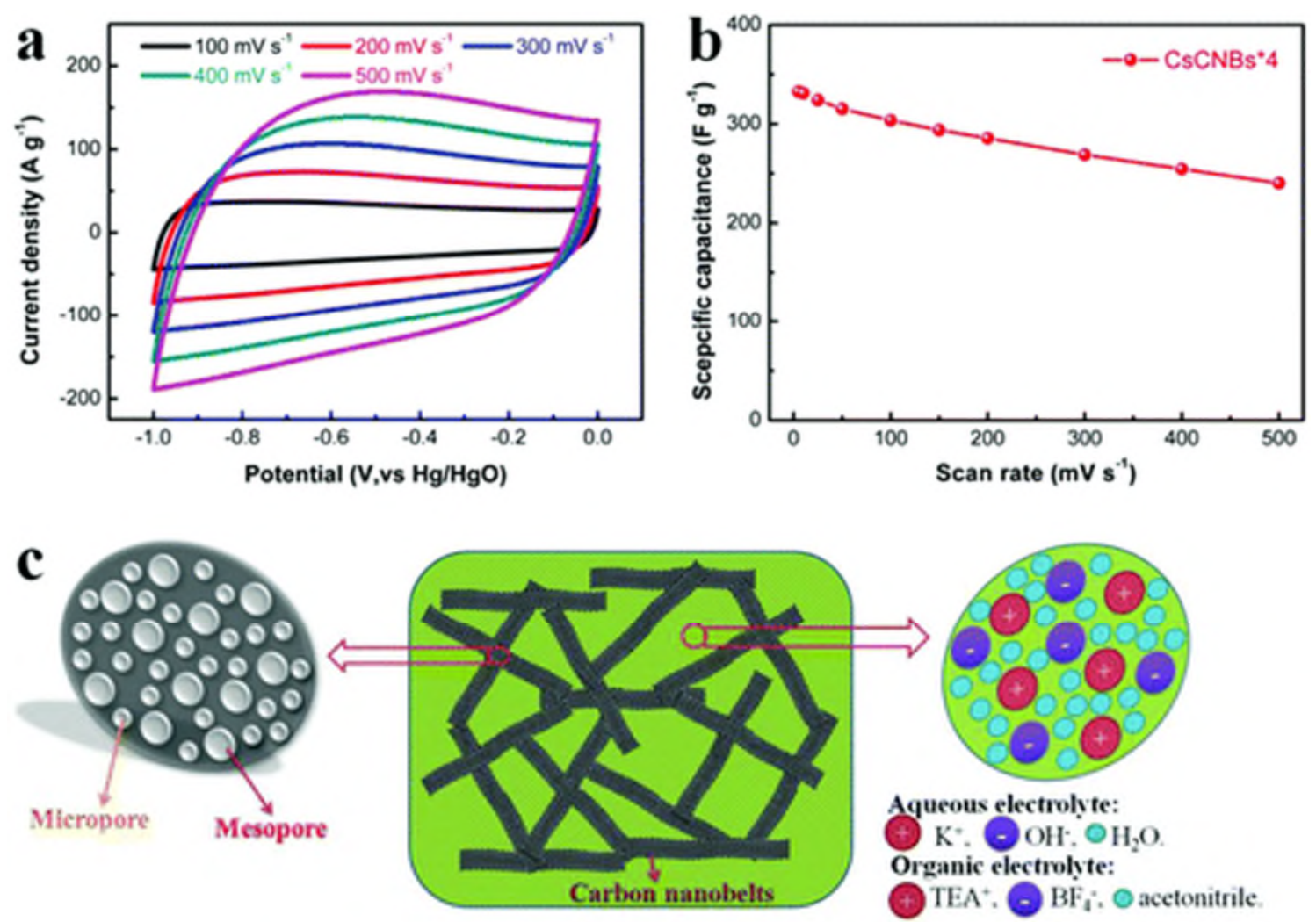

Fig. $8 \mathrm{CsCNBs}^{*} 4$ measured in a three-electrode system using $6 \mathrm{M} \mathrm{KOH}$ electrolyte: (a) $\mathrm{CV}$ curves obtained at various scanning rates ranging from 100 to $500 \mathrm{mV} \mathrm{s}^{-1}$; (b) specific capacitances at different potential scanning rates. (c) Schematic illustration of the electrode

$$
\text { prepared from } \mathrm{CsCNBs}^{*} 4 \text {. }
$$

\section{Conclusion}

In summary, hierarchical clews of carbon nanobelts (CsCNBs) with applications in highperformance supercapacitors have been prepared with phenolic resins as the carbon precursors through a facile and efficient two-step approach (carbonization and $\mathrm{KOH}$ activation). This twostep approach is a low-cost and easily industrialized method. From the optimized process, CsCNBs*4 with a specific surface area of up to $2291 \mathrm{~m}^{2} \mathrm{~g}^{-1}$ and a pore volume of up to 1.29 cm3 $\mathrm{g}^{-1}$ has been obtained. Fundamentally, the CsCNBs possess a three-dimensional conductive network structure, a hierarchically porous framework, and excellent hydrophilicity, which provide fast ion diffusion through the channels and a large ion adsorption/desorption surface to improve electrochemical performance of supercapacitors. The product exhibits high 
specific capacitances of $327.5 \mathrm{~F} \mathrm{~g}^{-1}$ and $281.5 \mathrm{~F} \mathrm{~g}^{-1}$ at a current density of $0.5 \mathrm{~A} \mathrm{~g}^{-1}$ in a threeand two-electrode system, respectively. Simultaneously, these results also reveal a high-rate capacitance $\left(72.2 \%\right.$ capacitance retention at $\left.500 \mathrm{mV} \mathrm{s}^{-1}\right)$ and stable cycling lifetime (95\% of the initial capacitance after 15000 cycles) in a three-electrode setup. Moreover, the CsCNBs*4 provides a high energy density of $29.8 \mathrm{~W} \mathrm{~h} \mathrm{~kg}^{-1}$ at a power density of $345.4 \mathrm{~W} \mathrm{~kg}^{-1}$ in $1 \mathrm{M}$ TEABF4/AN electrolyte. These inspiring results imply that this carbon material with a threedimensional conductive network structure possesses excellent potential for energy storage.

\section{Conflicts of interest}

There are no conflicts to declare.

\section{Acknowledgements}

This work was financially supported by the National Natural Science Foundation of China (No. 51202150, 51272161 and 21703141), the Science and Technology R\&D Program of Shenzhen (JCYJ20150324141711663, JCYJ20160422112012739 and JCYJ20170818100134570), the Program of Introducing Innovative Research Team in Dongguan (No. 2014607109), and the Foundation of the State Key Laboratory of Solidification Processing in NWPU (SKLSP201110).

\section{References}

A. C. Forse , C. Merlet , J. M. Griffin and C. P. Grey , J. Am. Chem. Soc., 2016, 138 , 5731 5744 CrossRef CAS PubMed $\$$.

J. Xie , P. Yang, Y. Wang, T. Qi , Y. Lei and C. Li , J. Power Sources, 2018, 401 , 213 -223 CrossRef CAS $\$$

X. Lu , L. Li , B. Song, K.-s. Moon , N. Hu , G. Liao , T. Shi and C. Wong, Nano Energy, 2015, $17,160-170$ CrossRef CAS $\mathbf{s}$.

B. Song, C. Sizemore , L. Li , X. Huang, Z. Lin , K.-s. Moon and C.-P. Wong, J. Mater. Chem. A, 2015, $3,21789-21796$ RSC \&.

D. Pech, M. Brunet, H. Durou, P. Huang, V. Mochalin , Y. Gogotsi , P.-L. Taberna and P. Simon, Nat. Nanotechnol., 2010, 5 , 651 —654 CrossRef CAS PubMed s. 
J. R. Miller and P. Simon, Science, 2008, 321 , 651 —652 CrossRef CAS PubMed \&.

H. Peng, G. Ma , K. Sun , Z. Zhang, Q. Yang and Z. Lei , Electrochim. Acta, 2016, 190 , 862 -871 CrossRef CAS 2 .

H. Yang , S. Kannappan , A. S. Pandian, J.-H. Jang, Y. S. Lee and W. Lu , J. Power Sources, 2015, $284,146-153$ CrossRef CAS \&.

M. Sevilla and R. Mokaya , Energy Environ. Sci., 2014, 7 , 1250 -1280 RSC .

L. Qie, W. Chen , H. Xu , X. Xiong, Y. Jiang, F. Zou , X. Hu , Y. Xin , Z. Zhang and Y. Huang, Energy Environ. Sci., 2013, 6 , 2497 -2504 RSC s .

Z. Dong, C. Jiang , H. Cheng, Y. Zhao, G. Shi , L. Jiang and L. Qu , Adv. Mater., 2012, 24 , 1856 - 1861 CrossRef CAS PubMed $\$$.

C. Long, X. Chen, L. Jiang, L. Zhi and Z. Fan, Nano Energy, 2015, 12 , 141 -151 CrossRef CAS 3.

Y. Jiang, J. Yan, X. Wu , D. Shan, Q. Zhou, L. Jiang, D. Yang and Z. Fan , J. Power Sources, 2016, 307,190 - 198 CrossRef CAS \& .

C. Chen, D. Yu , G. Zhao , B. Du , W. Tang, L. Sun , Y. Sun , F. Besenbacher and M. Yu , Nano Energy, 2016, 27 , 377 -389 CrossRef CAS \&.

H. Feng, H. Hu , H. Dong, Y. Xiao, Y. Cai , B. Lei , Y. Liu and M. Zheng, J. Power Sources, 2016, $302,164-173$ CrossRef CAS \&.

P. Yu , Z. Zhang, L. Zheng, F. Teng, L. Hu and X. Fang , Adv. Energy Mater., 2016, 6 , $1601111-1601120$ CrossRef 2 .

X. Tian, S. Zhu, J. Peng, Y. Zuo, G. Wang, X. Guo, N. Zhao, Y. Ma and L. Ma, Electrochim. Acta, 2017, 241, $170-178$ CrossRef CAS * .

Z. Li , B. Li , Z. Liu , D. Li , H. Wang and Q. Li , Electrochim. Acta, 2016, 190 , 378 -387 CrossRef CAS 3 .

B. Duan , X. Gao , X. Yao , Y. Fang , L. Huang, J. Zhou and L. Zhang , Nano Energy, 2016, $27,482-491$ CrossRef CAS \&.

J. Zhao , H. Lai , Z. Lyu , Y. Jiang, K. Xie , X. Wang, Q. Wu , L. Yang, Z. Jin , Y. Ma , J. Liu and Z. Hu , Adv. Mater., 2015, 27 , 3541 —3545 CrossRef CAS PubMed \&.

T. Zhai , X. Lu , H. Wang, G. Wang, T. Mathis , T. Liu , C. Li , Y. Tong and Y. Li , Nano Lett., 2015, 15 , 3189 -3194 CrossRef CAS PubMed \$.

S.-Z. Zeng, N.-Z. Jin , H.-L. Zhang, B. Hai , X.-H. Chen and J. Shi , RSC Adv., 2014, 4 , 18676 - 18682 RSC \&.

S.-Z. Zeng, X. Zeng, W. Tu, Y. Yao, L. Yu , H. Wu, W. Jin, H. Huang and J. Zou, J. Mater. Chem. A, 2017, 5 , $23209-23220$ RSC \&. 
J. Wang and S. Kaskel , J. Mater. Chem., 2012, 22 , 23710 -23725 RSC \&

L. Zhu , Q. Gao, Y. Tan , W. Tian, J. Xu , K. Yang and C. Yang, Microporous Mesoporous Mater., 2015, 210, 1 -9 CrossRef CAS \& .

J. Hou , K. Jiang, R. Wei , M. Tahir , X. Wu , M. Shen , X. Wang and C. Cao , ACS Appl. Mater. Interfaces, 2017, 9 , 30626 -30634 CrossRef CAS PubMed s.

A. C. Ferrari and D. M. Basko, Nat. Nanotechnol., 2013, 8 , 235 -246 CrossRef CAS PubMed 3 .

B. You , L. Wang, L. Yao and J. Yang, Chem. Commun., 2013, 49, 5016 -5018 RSC \& .

S. Hu , S. Zhang, N. Pan and Y.-L. Hsieh , J. Power Sources, 2014, 270 , $106-112$ CrossRef CAS 3.

V. Barranco, M. A. Lillo-Rodenas, A. Linares-Solano, A. Oya , F. Pico, J. Ibanez , F. AgulloRueda, J. M. Amarilla and J. M. Rojo, J. Phys. Chem. C, 2010, 114, 10302 -10307 CrossRef CAS 2 .

S.-Z. Zeng, Y. Yao, X. Zeng, Q. He, X. Zheng, S. Chen, W. Tu and J. Zou, J. Power Sources, 2017, 357, 11 - 18 CrossRef CAS \& .

J. Hu , H. Wang, Q. Gao and H. Guo, Carbon, 2010, 48, 3599 -3606 CrossRef CAS \&.

B. You , F. Kang, P. Yin and Q. Zhang, Carbon, 2016, 103 , $9-15$ CrossRef CAS s .

B. You , J. Jiang and S. Fan , ACS Appl. Energy Mater., 2014, 6 , 15302 -15308 CrossRef CAS PubMed 3.

S. Z. Zeng, Y. Yao, L. Huang, H. Wu , B. Peng, Q. Zhang, X. Li , L. Yu , S. Liu , W. Tu , T. Lan , X. Zeng and J. Zou , Chem. - Eur. J., 2018, 24 , 1988 -1997 CrossRef CAS PubMed 4.

S. Pohlmann , B. Lobato , T. A. Centeno and A. Balducci , Phys. Chem. Chem. Phys., 2013, $15,17287-17294$ RSC \&.

Y. Yao, H. Wu , L. Huang, X. Li , L. Yu, S. Zeng, X. Zeng, J. Yang and J. Zou, Electrochim. Acta, 2017, 246, 606 -614 CrossRef CAS \$.

J. He , Y. Chen , W. Lv , K. Wen, C. Xu , W. Zhang, Y. Li , W. Qin and W. He , ACS Nano, 2016, 10 , 10981 - 10987 CrossRef CAS PubMed .

K. O. Oyedotun , M. J. Madito, A. Bello, D. Y. Momodu , A. A. Mirghni and N. Manyala , Electrochim. Acta, 2017, $245,268-278$ CrossRef CAS 3.

D. Wang, Z. Geng, B. Li and C. Zhang, Electrochim. Acta, 2015, 173, 377 - 384 CrossRef CAS 2 .

Y. Yao, Q. Zhang, P. Liu , L. Yu, L. Huang, S.-Z. Zeng, L. Liu , X. Zeng and J. Zou , RSC Adv., 2018, 8, $1857-1865$ RSC \&. 
B. You , L. Wang, N. Li and C. Zheng, ChemElectroChem, 2014, 1, 772 -778 CrossRef CAS 2.

J. Zhang, G. Chen , Q. Zhang , F. Kang and B. You , ACS Appl. Energy Mater., 2015, 7 , $12760-12766$ CrossRef CAS PubMed 2 .

S. Feng, W. Li , J. Wang, Y. Song, A. A. Elzatahry, Y. Xia and D. Zhao, Nanoscale, 2014, $6,14657-14661 \mathrm{RSC}$.

P. Yang , J. Xie and C. Zhong, ACS Appl. Energy Mater., 2018, 1 , 616 -622 CrossRef CAS 3.

M. Zou , W. Zhao , H. Wu , H. Zhang, W. Xu , L. Yang, S. Wu , Y. Wang, Y. Chen, L. Xu and A. Cao , Adv. Mater., 2018, 30 , 1704419 - 1704427 CrossRef PubMed « .

K. Song, W.-L. Song and L.-Z. Fan, J. Mater. Chem. A, 2015, 3 , $16104-16111$ RSC \& .

K.-J. Huang, J.-Z. Zhang, G.-W. Shi and Y.-M. Liu , Electrochim. Acta, 2014, 132 , 397 403 CrossRef CAS $\$$

L. Yu , S. Zeng , X. Zeng , X. Li , H. Wu , Y. Yao , W. Tu and J. Zou , Materials, 2018, 11 , 556 - 567 CrossRef PubMed $\$$.

Y. An, Y. Yang, Z. Hu , B. Guo, X. Wang, X. Yang, Q. Zhang and H. Wu, J. Power Sources, 2017, $337,45-53$ CrossRef CAS 2.

Y. Li , G. Wang, T. Wei , Z. Fan and P. Yan , Nano Energy, 2016, 19, 165 -175 CrossRef CAS 3 .

M. Lee , G. P. Kim , H. Don Song, S. Park and J. Yi , Nanotechnology, 2014, 25 , 345601 245608 CrossRef PubMed $\$$.

Y.-Q. Zhao, M. Lu , P.-Y. Tao, Y.-J. Zhang, X.-T. Gong, Z. Yang, G.-Q. Zhang and H.-L. Li , J. Power Sources, 2016, 307 , 391 —400 CrossRef CAS \&.

M. Wahid, G. Parte, D. Phase and S. Ogale, J. Mater. Chem. A, 2015, 3, 1208 -1215 RSC 3.

J. Chmiola , C. Largeot , P.-L. Taberna , P. Simon and Y. Gogotsi , Angew. Chem., 2008, 120 , 3440 - 3443 CrossRef $\$$.

P. Cheng, S. Gao, P. Zang, X. Yang, Y. Bai , H. Xu , Z. Liu and Z. Lei , Carbon, 2015, 93 , 315 -324 CrossRef CAS $\$$.

L. Hu, J. W. Choi , Y. Yang, S. Jeong, F. La Mantia, L. F. Cui and Y. Cui, Proc. Natl. Acad. Sci. U. S. A., 2009, 106 , 21490 - 21494 CrossRef CAS PubMed \&. 
2019-03-27

High-performance supercapacitors based on hierarchically porous carbons with a three-dimensional conductive network structure

Zou, Jizhao

Royal Society of Chemistry

Zou J, Tu W, Zeng S-Z, et al., (2019) High-performance supercapacitors based on hierarchically porous carbons with a three-dimensional conductive network structure. Dalton Transactions,

Volume 48, Issue 16, April 2019, pp. 5271-5284

https://doi.org/10.1039/C9DT00261H

Downloaded from Cranfield Library Services E-Repository 